Check for updates

Reading

Cite this as: BMJ 2020;371:m4155 http://dx.doi.org/10.1136/bmj.m4155 Published: 27 October 2020

\section{Covid-19: Hospital discharges during pandemic were often chaotic, says watchdog}

David Oliver

Many patients discharged from hospitals in England in the past six months under new arrangements to free up beds did not get the follow-up support they needed, concludes a report from HealthWatch, which represents patients' interests in England. ${ }^{1}$

Sometimes basic checks such as whether people needed transport to get home were missed, says the report. In many cases people reported feeling unprepared to leave hospital and confused about whom to contact for further information. Many reported never receiving a follow-up assessment after they left hospital. The report also highlighted concern that some patients were not tested for covid-19 while in hospital or did not receive their test results before discharge.

The report was based on interviews with 590 patients or their carers on their experiences with discharge from hospital between March and August 2020.

On 19 March the government issued national guidance to help hospitals free up 15 ooo beds to cope with the demand from patients with covid-19. The "Discharge to assess" model aimed to help people leave hospital more quickly by having their ongoing care needs assessed in their own home or care home. ${ }^{2}$

Some patients thought that their discharge from hospital was rushed, with a fifth $(19 \%)$ feeling that they were not prepared. A third (27\%) of patients discharged at night felt unprepared, and almost two thirds $(64 \%)$ of those discharged at night weren't asked whether they needed help with transport.

The report, written in conjunction with British Red Cross, found that $61 \%$ of patients said they received no information about the new discharge arrangements, with many families not being kept up to date at a time when visiting was heavily restricted because of pandemic measures.

The new guidance required patients to be provided with a single point of contact if they need further health advice after discharge, but $35 \%$ of respondents did not receive this information.

The report found that $82 \%$ of patients did not receive a follow-up visit and assessment by a healthcare professional, and nearly a fifth of those who did not receive a visit thought that they had significant unmet needs.

A quarter of patients (24\%) were not tested for covid-19 during the time they spent in hospital. Despite the policy stating that all patients discharged to a care home should be tested, the survey found that $26 \%$ of respondents who were discharged to a home were not. Thirty per cent of patients did not receive their test results before being discharged, which could put family and carers at risk and be a particular problem for care homes, the report found.

Robert Francis, chair of Healthwatch England, said, "It's essential that we learn from what people have shared with us about the impact that a poorly handled discharge can have on them and their loved ones. Taking action now will not only reduce the risk to patients but will also help improve the way people leave hospital in the future."

Tash Masud, president of the British Geriatrics Society, commented, "A positive experience of being discharged from hospital can make all the difference for an older person living with frailty or other long term conditions. As new NHS discharge arrangements are implemented, it is critical that the gap between rhetoric and reality exposed in this report is eliminated so that people feel safe, supported, and ready for the next stage of their recovery."

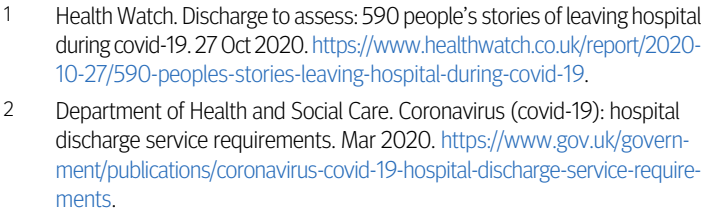

This article is made freely available for use in accordance with BMJ's website terms and conditions for the duration of the covid-19 pandemic or until otherwise determined by BMJ. You may use, download and print the article for any lawful, non-commercial purpose (including text and data mining) provided that all copyright notices and trade marks are retained. 